\title{
A Rare Cause of Acute Upper Gastrointestinal Hemorrhage
}

\author{
T.S. de Vries Reilingh ${ }^{\mathrm{a}, \mathrm{b}} \quad$ V.A. Postma ${ }^{\mathrm{a}} \quad$ T.J. Aufenacker ${ }^{\mathrm{a}, \mathrm{c}}$ \\ L.J.A. Strobbe ${ }^{a} \quad$ C. Rosman ${ }^{a}$
}

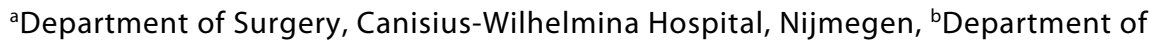
Surgery, St. Antonius Hospital, Nieuwegein, and 'Department of Surgery, Rijnstate Hospital, Arnhem, The Netherlands

\author{
Key Words \\ Gastrointestinal hemorrhage $\cdot$ Pancreas $\cdot$ Pseudocyst
}

\begin{abstract}
Acute upper gastrointestinal tract hemorrhage represents a frequent morbidity which can be localized and treated endoscopically. When endoscopic treatment alone is failing, radiological or surgical treatment may be warranted. A case history will be presented regarding a rare cause of intestinal hemorrhage with an extraordinary course of illness.
\end{abstract}

\section{Case Report}

A 56-year-old man suffering from diabetes and hypertension was admitted to the neurology department in a hospital elsewhere with signs of epileptic seizure. After a brief period, the patient went into hypovolemic shock and was transferred to the intensive care unit. A diagnostic laparotomy with gastrotomy was performed, at which over 3 liters of blood were found, but no active bleeding. The site of origin of hemorrhage was suspected at the gastroesophageal junction, although no peptic ulcer could be discovered.

Gastroscopy was performed 1 day later, demonstrating a large, ulcerating tumor at the cardia, of which biopsies were taken. Because the patient was now diagnosed with a bleeding tumor at the gastroesophageal junction, he was transferred to the ICU of the Canisius-Wilhelmina Hospital in Nijmegen (in formation with the Radboud University Hospital comprising the Esophagus Centre Eastern Netherlands, SCON). The patient remained hemodynamically stable. Histological results displayed ulcerative changes, but no signs of malignancy. A computed tomography (CT) scan was performed, showing a large tumor at the gastroesophageal junction, extending towards the pancreatic tail (fig. 1). Differential diagnosis: malignant tumor or hematoma at the posterior wall of the stomach. A second gastroscopy with new biopsies, 8 days later, proved the same results.

At the time of the third gastroscopy, 14 days after the initial laparotomy, the ulcer was no longer discernable. A second CT scan revealed a remarkable decline of the entire process, emanating from the pancreatic tail as a pseudocyst (ig. 2). Further investigation revealed a history of alcohol abuse in this patient. In conclusion, our patient experienced hypovolemic shock following massive gastrointestinal hemorrhage caused by a burst-through of a pancreatic pseudocyst to the stomach. 


\begin{tabular}{r|l|l|l} 
Case Reports $/ h$ & $\begin{array}{l}\text { Case Rep Gastroenterol 2009;3:400-403 } \\
\text { D01: 10.1159/000256908 }\end{array}$ & Published online: November 21, 2009 & $\begin{array}{l}\text { O 2009 S. Karger AG, Basel } \\
\text { ISSN 1662-0631 } \\
\text { www.karger.com/crg }\end{array}$ \\
\hline
\end{tabular}

\section{Discussion}

The incidence of upper gastrointestinal hemorrhage in The Netherlands is $45-70$ per 100,000 per year, most of which are caused by peptic ulcers of the stomach and duodenum $[1,2]$. A pseudocyst of the pancreas consists of one or several collections of pancreatic fluid, surrounded by inflamed pancreatic tissues. The wall is formed by the enclosing structures, i.e. stomach, transverse colon or omentum. The pseudocyst is usually connected to the pancreatic duct. The distinctive feature between a genuine cyst and a pseudocyst is the lack of an epithelial layer. Pseudocysts of the pancreas arise as a result of episodes of acute pancreatitis or blunt force abdominal trauma. The cause is often disruption or obstruction of the pancreatic duct, with subsequent accumulation of pancreatic fluids, containing high concentrations of pancreatic enzymes. In acute pancreatitis, (pseudo)cyst and necrosis can be difficult to distinguish by contrastenhanced CT scan [3], whereas magnetic resonance imaging (MRI) is distinctive [4].

Pseudocysts can damage adjacent arteries by means of mechanical pressure and digestion by pancreatic enzymes, hereby causing the formation of pseudoaneurysm with possible subsequent hemorrhage into the pancreatic duct. Usually, this involves the splenic artery, but also the gastroepiploic arteries and gastroduodenal branches can be affected [5].

The old motto is to drain pseudocysts larger than $6 \mathrm{~cm}$ or existing longer than 6 weeks [6], although literature on the subject scarcely supports this. The advice is to drain only symptomatic pseudocysts [7]. The possibilities for drainage are to marsupialize the pseudocyst through laparotomy or laparoscopy to the stomach or jejunum, or to perform resection of the pancreatic tail. Moreover, marsupialization can be achieved by endoscopy or percutaneously. There is no evidence to favor any method [6]. Pseudoaneurysms or hemorrhages are eligible for endovascular embolization, and transgastric drainage of cysts is contraindicated during hemorrhages, unless embolization is performed first [2]. Case series and case reports in the available literature on hemorrhaging pseudocysts all advocate endovascular embolization, followed by resection of the pancreatic tail [5, 8-13].

Our patient was diagnosed with hemorrhaging pseudocyst 16 days after admission and initial laparotomy. Because of the improving clinical condition and decline of the pseudocyst on CT scan, it was decided to pursue a 'watchful waiting' policy and to only intervene in case of hemodynamic instability. The initial plan was to perform pancreatic tail resection after clinical recovery; however, ultrasonography and CT scan revealed a rapid decline and full disappearance of the pseudocyst. Surgical intervention was no longer necessary. Our patient made a full recovery and has adjusted his life style.

In all case reports, operative intervention is advocated, precipitated by endovascular embolization in case of serious hemodynamic instability. One case series of 16 patients reports a $62 \%$ mortality rate, in which endovascular embolization is combined with pancreatic tail resection [13]. There are no case series in which patients are treated exclusively conservatively. There is evidence to support the role of angiography in case of acute upper gastrointestinal hemorrhage, simultaneously offering the possibility for endovascular treatment $[2,5,8-13]$. This might have been an opportunity to take advantage of in our patient. Embolizing the splenic artery does not inevitably necessitate splenectomy, for the remaining blood supply to the spleen is routed through the vasa brevia, which should be sufficient. Furthermore, the course of our patient proves that surgical intervention such as pancreatic tail resection is not always an absolute necessity. 


\begin{tabular}{r|l|l|l} 
Case Reports $h$ & $\begin{array}{l}\text { Case Rep Gastroenterol 2009;3:400-403 } \\
\text { D01: 10.1159/000256908 }\end{array}$ & Published online: November 21, 2009 & $\begin{array}{l}\text { O 2009 S. Karger AG, Basel } \\
\text { ISSN 1662-0631 } \\
\text { www.karger.com/crg }\end{array}$ \\
\hline
\end{tabular}

\section{Conclusion}

Hemorrhaging pancreatic pseudocyst can be potentially lethal and warrants an acute intervention. However, surgery is nowadays not the only option for treatment, as possibilities in radiological endovascular diagnostics and techniques are increasing and will eventually be the first step in treating acute upper gastrointestinal hemorrhage.

Fig. 1. Initial CT scan images during the ICU period, demonstrating a large tumor in the gastroesophageal junction extending towards the pancreatic tail.
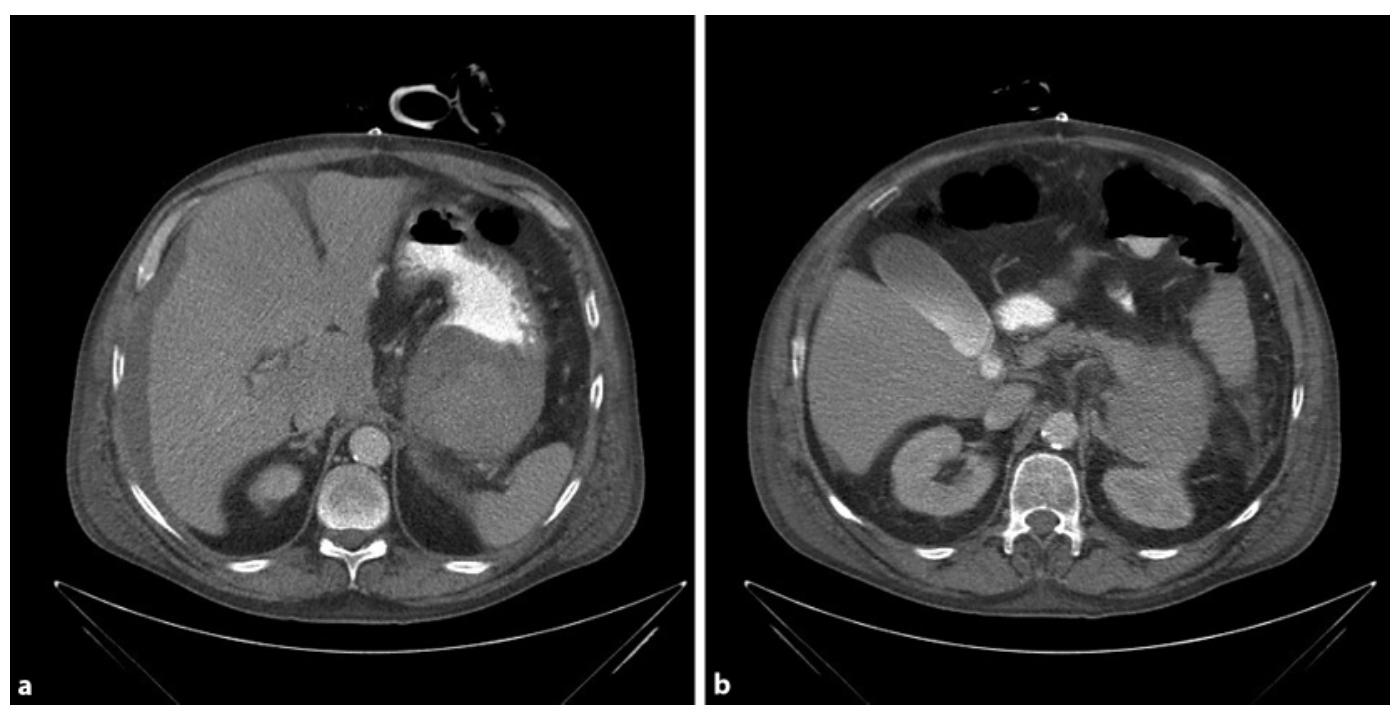

Fig. 2. CT scan image after 1 month. Note the marked decrease in size of the pancreatic pseudocyst compared to figure 1 .

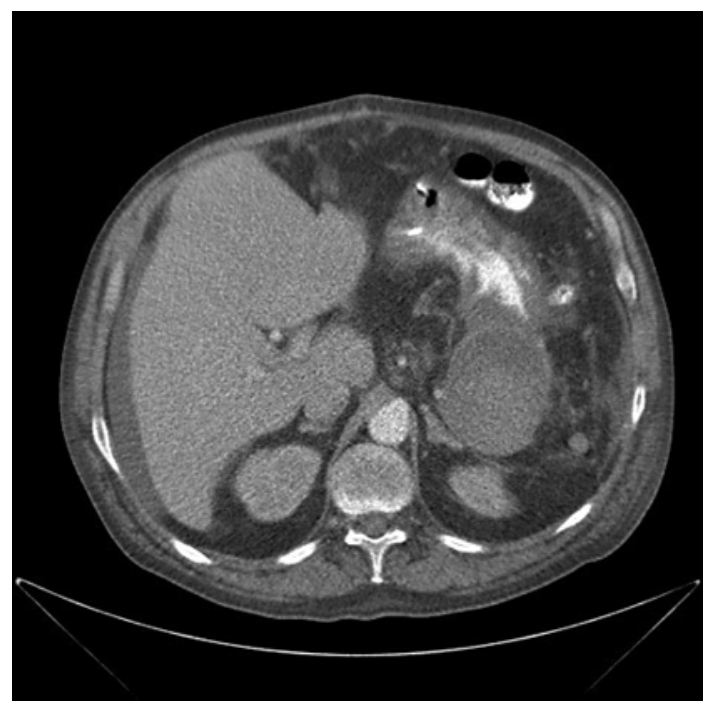




\section{References}

1 Boey J, Wong J: Perforated duodenal ulcers. World J Surg 1987;11:319-324.

2 Besselink MGH, Van Santvoort HC, Bollen TL, et al: Describing computed tomography findings in acute necrotizing pancreatitis with the Atlanta classification: an interobserver agreement study. Pancreas 2006;33:331-335.

3 Van Santvoort HC, Bollen TL, Besselink MGH, et al: Describing peripancreatic collections in severe acute pancreatitis using morphologic terms: an international interobserver agreement study. Pancreatology 2008;8:593-599.

4 Risti B, Marincek B, Jost R, et al: Hemosuccus pancreaticus as a source of obscure upper gastrointestinal bleeding. Three cases and literature review. Am J Gastroenterol 1995;90:1878.

5 Bivins BA, Sachatello CR, Chuang VP, et al: Hemosuccus pancreaticus: gastrointestinal hemorrhage due to rupture of a splenic artery aneurysm into the pancreas. Arch Surg 1978;113:751-753.

6 Kiviluoto T, Schroder T, Kivilakso E, et al: Acute hemorrhage associated with pancreatic pseudocyst and chronic pseudocyst and chronic pancreatitis. Ann Chir Gynaecol 1984;73:214.

7 El Hamel A, Parc R, Adda G, et al: Bleeding pseudocyst and pseudoaneurysms in chronic pancreatitis. Br J Surg 1992;78:1059-1063.

8 Bender JS, Bouwman DL, Levison MA, et al: Pseudocyst and pseudoaneurysms: surgical strategy. Pancreas 1995;10:143-147.

9 Masatsugu T, Yamaguchi K, Yokohata K, et al: Hemorrhagic pseudocyst and pseudocyst with pseudoaneurysm successfully treated by pancreatectomy: reports of three cases. J Hepatobiliary Pancreat Surg 2000;7:432-437.

10 Carr JA, Cho JS, Shepard AD, et al: Visceral pseudoaneurysms due to pancreatic pseudocysts: rare but lethal complications of pancreatitis. J Vasc Surg 2000;32:722-730. 